Original Research Article

\title{
Avifaunal diversity in the Deer Park of Hauz Khas, New Delhi
}

Singh, Jagjeet ${ }^{1}$; Nupur ${ }^{1}$; Goyal, Vivek ${ }^{2}$; Dalal, Poonam ${ }^{3}$ and Malik, Vinay ${ }^{1}$

${ }^{1}$ Department of Zoology, Maharshi Dayanand University, Rohtak, Haryana, India

${ }^{2}$ Govt. National College, Sirsa, Haryana, India

${ }^{3}$ Govt. SSS Gochhi, Jhajjar, Haryana, India

Corresponding Author: vinaymalik71@gmail.com

\section{A R T I C L E I N F O}

Received: 30 January 2018 | Accepted: 22 April 2018 | Published Online: 15 August 2018

DOI: $10.31786 / 09756272.18 .9 .1 .105$

EOI: 10.11208/essence.18.9.1.105

Article is an Open Access Publication.

This work is licensed under Attribution-Non Commercial 4.0 International

(https://creativecommons.org/licenses/by/4.0/)

CThe Authors (2018). Publishing Rights @ MANU_ICMANU \& ESSENCE-IJERC.

\section{A B S T R A C T}

Avian diversity of the Deer Park located at Hauz Khas in New Delhi was studied from May 2017 to April 2018. Direct observations were followed to study the different habits of the birds. Photographs of the spotted birds were taken for identification. A total of 20 bird species of 19 Genus belonging to 15 different families placed in 10 different orders were observed. The Muscicapidae $(n=3)$ was the most abundant family while order Passeriformes $(n=10)$ supported highest number of species $(50 \%)$. The $45 \%$ species $(n=9)$ exhibited the stable population trend. Omnivorous birds $(n=9)$ were the most dominant birds in the park. All the found birds were resident species falling in the least concerned category of the IUCN conservation status. This pilot study indicates the Deer Park an important habitat for the resident species of the area.

\section{K E Y W O R D S}

Avian diversity | Deer Park | New Delhi

\section{I T A T I O N}

Singh, Jagjeet; Nupur; Goyal, Vivek; Dalal, Poonam and Malik, Vinay (2018): Avifaunal diversity in the Deer Park of Hauz Khas, New Delhi. ESSENCE Int. J. Env. Rehab. Conserv. IX (1): 34-37. 


\section{Introduction}

New Delhi the national capital of India faces huge anthropogenic activities since independence. It is the second most populated city of India having semi arid type of climate. Rapid expansion in population by constant immigration poses severe threat to Delhi's life supporting systems. Constant urbanisation is deleteriously affecting the species biodiversity of the expanding cites of India. The major associated effects include the change of land use, destruction of habitat, pollution and altering of geochemical cycles (Michael, 2002). All these activities disturb the natural harmony of the ecosystems and favour a new interdepend ence among the wild life species colonizing that place. In spite of all these bird species due to heterogeneous feeding habits and flying ability invade and customize the inhabitable urban areas. Mostly the generalist species dominate such areas. There are only a few studies listing the avian fauna of various artificial green landscapes, spaces or parks of New Delhi (Chhikara and Hooda, 2007; Khera et al. 2009; Prakash and Manasvini, 2013; Turaga, 2015). The present study evaluates the avian diversity supported by the Deer Park, Hauz Khas of New Delhi.

\section{Study site}

The study was carried out in and around Deer Park Figure 1. It comes under the Southern Ridge of Delhi which has coordinates $28.5566{ }^{\circ} \mathrm{N}$ and $77.1959{ }^{0}$ E. It makes up a total area of 60 hectares including the District Park and Rose Garden. The entire area supports good diversity of trees belonging to Fabaceae, Verbenaceae, Apocyanaceae, Meliaceae, Rubiaceae, Moracaea, Myrtaceae, Bignoniaceae and many other families.

\section{Material and Methods}

Field survey was conducted from May 2017 to April 2018 by making weekend visits from 7:00 am to $9: 00$ am and $04: 00 \mathrm{pm}$ to $6: 00 \mathrm{pm}$. Observation of birds was done through naked eyes and photographs were taken by camera - Canon $6 \mathrm{~d}$ Mark 2. Identification of species was done with the help of following Ali and Ripley, 1987; Kazmierczak, 2000; Grimmett et al., 2007. Birds were clicked from two or three different angles for cor- rect identification of species. IUCN Red List, 2018 was used as references to find out ecologi-

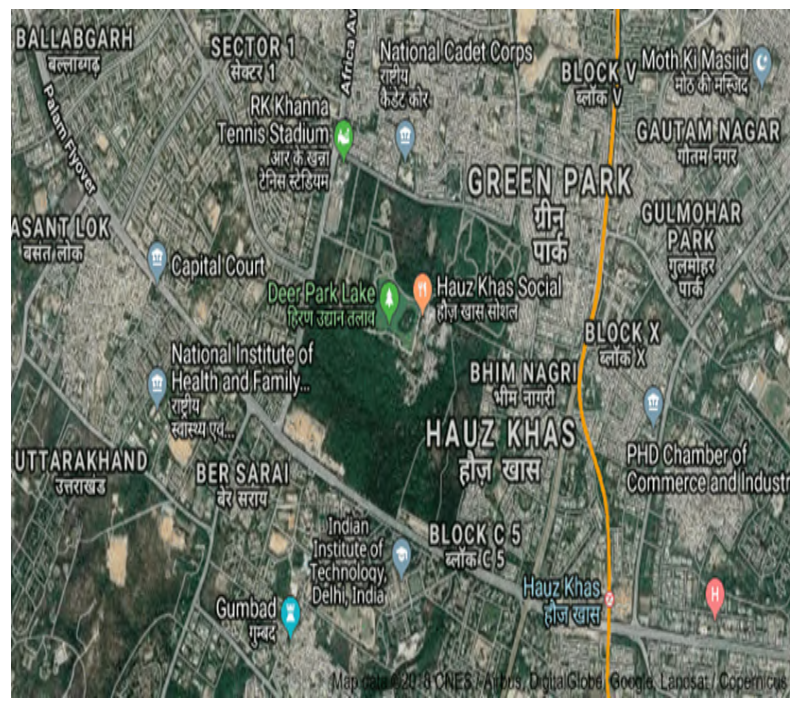

Fig 1: Satellite Map of Deer Park, Hauz Khas, New Delhi

cal level and population trend. Feeding habits were based on direct observation of birds in Deer Park, New Delhi.

Percent $(\%)=\underline{\text { number of species of particular family }} \times 100$ occurrence Total number of species

\section{Results and Discussion}

A total of 20 species of birds belonging to 10 orders and 15 families were observed in this preliminary study of one year in the Deer Park, Hauj Khas, New Delhi, Table 1. All the reported birds were resident species and are commonly found nearly all over the India. Order Passeriformes with 10 species in 6 families has the highest diversity accounting $50 \%$ of the spotted species in the park, commonly found nearly all over the India. Order Passeriformes with 10 species in 6 families has the highest diversity accounting 50\% Table 1: Bird species sighted at Deer Park, New Delhi of the spotted species in the park, The Muscicapidae $(n=3)$ was the most abundant family with 20 percent occurrence followed by Corvidae, Sturnidae and Columbidae with 2 species each while rest all the eleven families were represented by single species each, Table 2 . Percentage occurance of families is clear indication of the dominancy of families over other. Percentage ocurance 


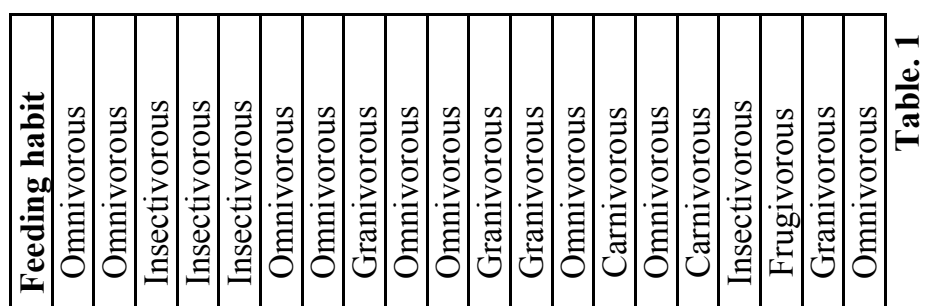

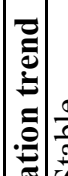

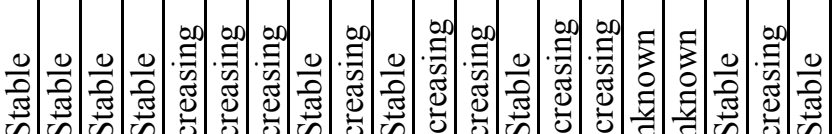

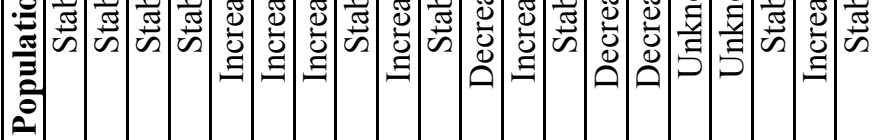

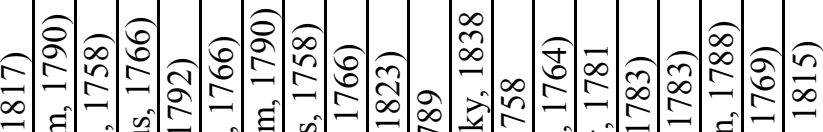

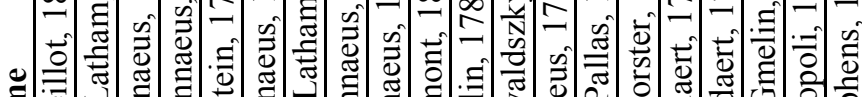
竎

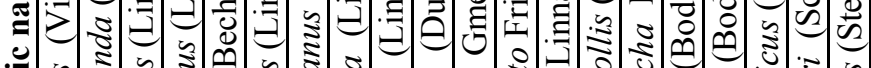

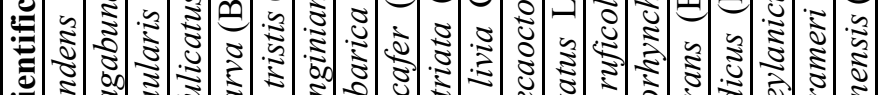

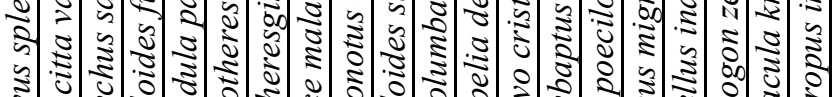

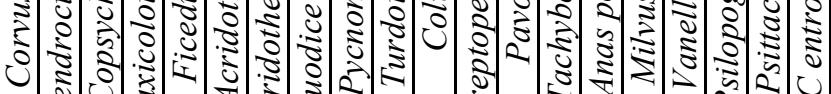

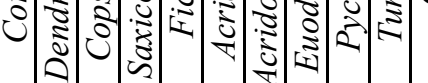

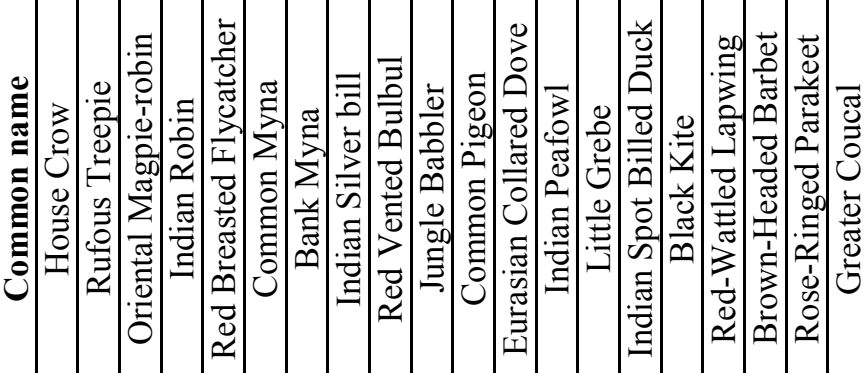

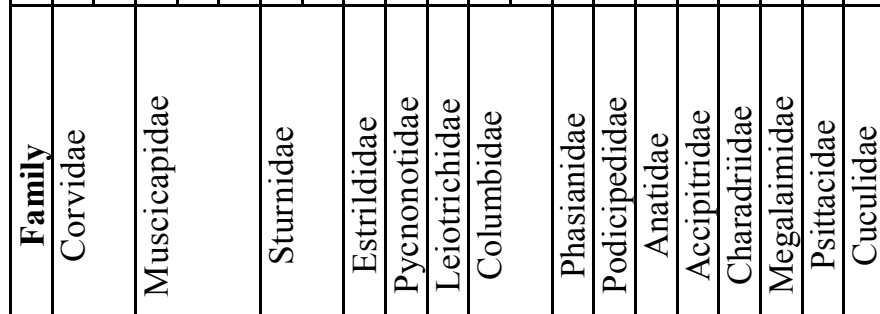

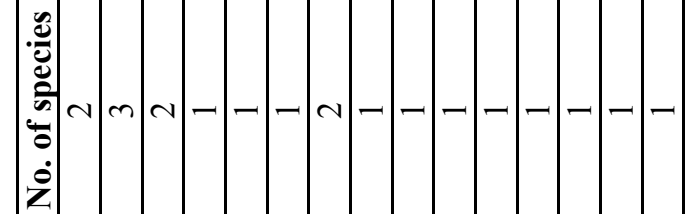

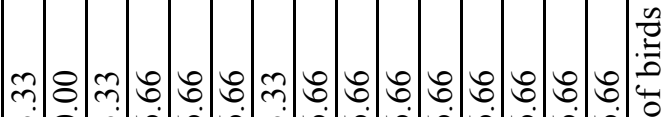

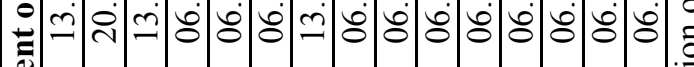

¿.

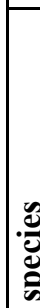
$\dot{8}$
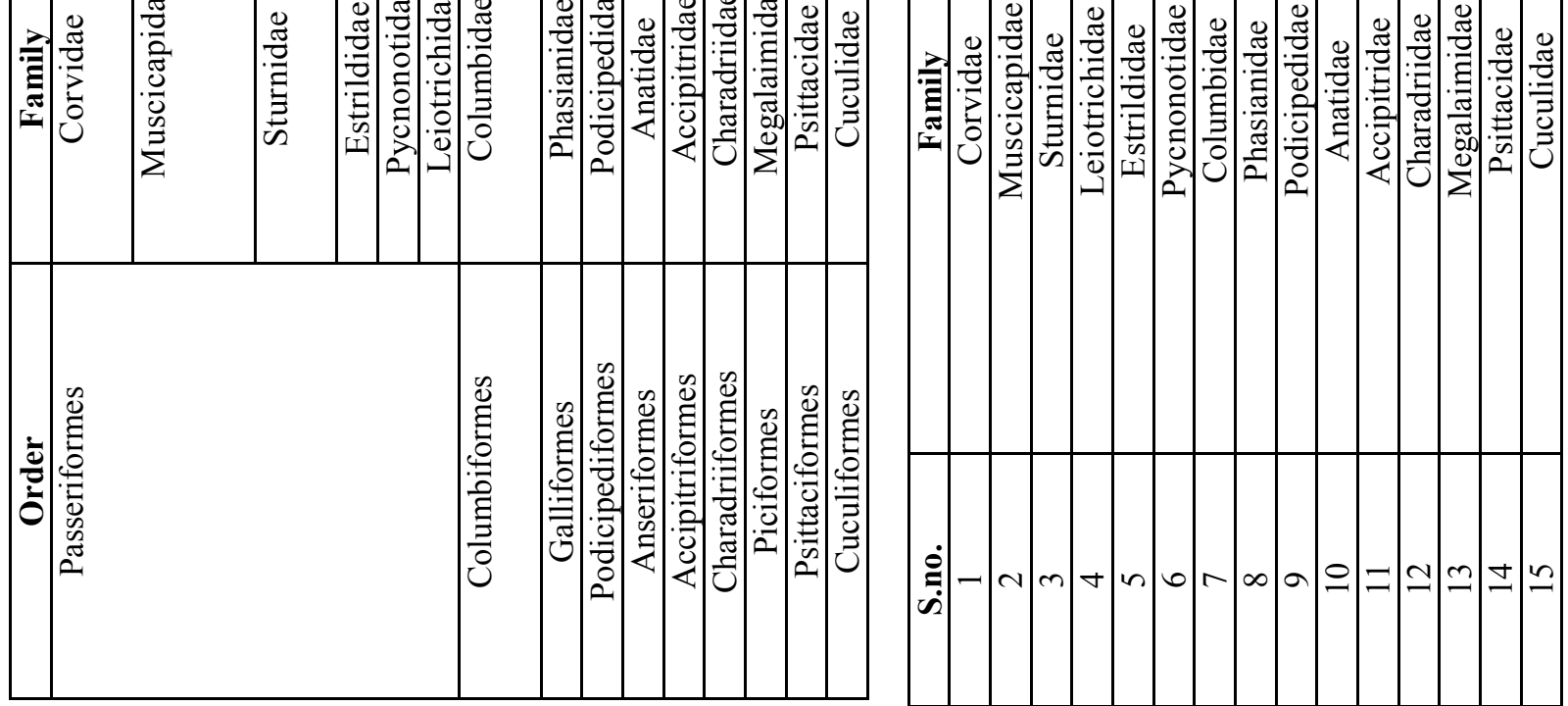

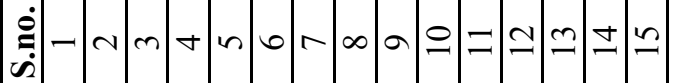


also reveals about local ecological distri also reveals about local ecological distribution of resources. Those natural resources are abundant which are supported by family having highest percentage occurrence.

Birds showed high adaptation to environment and exhibit different feeding habits. Feeding habits are reliable indicator of bird's behaviour. Variety of feeding habits were observed in the spotted birds. The highest obsereved avian species were omnivorous ( 9 species, 45\%) followed by insectivorous and granivorous with equal (4 species, 20\%) each, carnivorous (2 species, 10\%) and least were frugivorous ( 1 species, 5\%) Fig. 2. The high percent of omnivorous species feeding upon grains, fruits, insects and human food remains indicated unpredictability and low availability of the preferred food resource. Insectivorous and granivorous species suggested a constant availablility of food all year round. Only few fruit trees accounted for merely one frugivorous bird species in the Deer Park. Milvus migrans was only bird of prey and top carnivore. Anus poecilorhyncha and Tachybaptus rificollis were aquatic feeder which feed on algae, grasses, small invertebrates, fishes and ampbibians. Variety of feeding habits keep environment healty and clean. Water bodies inside park and park zones were kept clean and protected from insects and aquatic weeds.

\section{Conclusion}

New Delhi supports nearly 434 bird species in 17 orders with 59 families and the present study 17 orders with 59 families and the present study of Deer Park recorded only $4.6 \%$ species, $59 \%$ orders and 25\% families of the birds of New Delhi (Singh et al., 2017).This low number may be attributed to the complete abseance of shurbs in the Deer Park (Khera et al., 2009). Habitat loss with alteration in landscape is the common cause for diversity loss in cities. Parks in the urban cities are also noisy place due to vehicles and people activities concentrated in morning and evening. All these disturbances make city parks support selected species of small birds. In Deer Park, Hauz Khas, New Delhi human interferences in the form of jogging, walking, kitty parties, mobile tower radiations and vehicular pol-

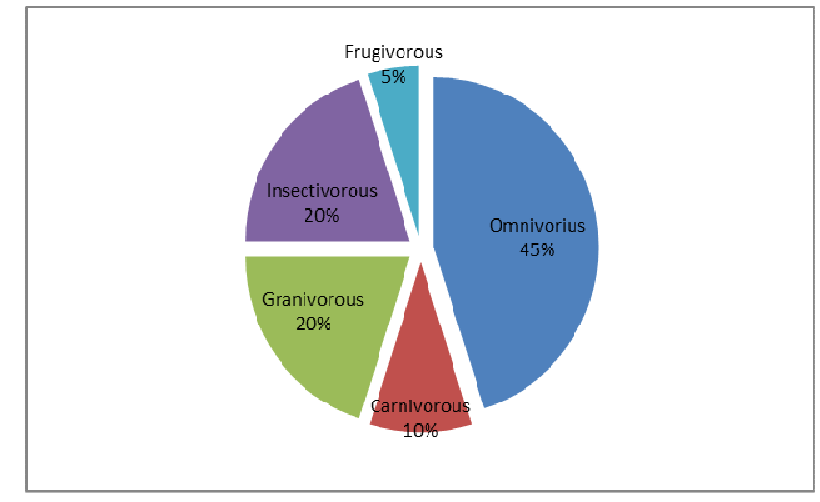

Fig. 2: Feeding habits of the birds of Deer Park, New Delhi

lution affect the avian species. It is concluded here that restricting the human activities with expansion of green areas with high structural diversity can be helpful in conserving the urban avian diversity.

\section{References}

Ali, S. and Ripley, S. D. (1987): Birds of India and Pakistan., 223-669.

Chikkara, M. and Hooda, S. (2007): Investigation of Avianfauna of Central Ridge of Delhi, The Union Territory. Dissertation:41-48.

Grimmett, R. (2007): Birds of the Indian Subcontinent-Oxford University Press. http://www.iucnredlist.org/ 10 April, 2018.

Kazmierczak, K. and Perlo, B. (2000): A field guide to the birds of India, Sri Lanka, Pakistan, Nepal, Bhutan, Bangladesh, and the Maldives. Om Book Service.

Khera, N. (2009): Interrelationship of birds and habitat features in urban greenspaces in Delhi, India. Urban Forestry \& Urban Greening, 8(3): 187-196.

Michael, M. L. (2002): Urbanization, biodiversity, Conservation. Bioscience 52, 883-890.

Prakash, S. and Manasivini (2013): Urban Avifaunal Diversity: An Indicator of Anthropogenic Pressure in Southern Ridge of Delhi. Adv.Biores. 4 (2), 135-144.

Singh, M. (2017): Avifaunal Composition of Jawaharlal Nehru University Campus, New Delhi Curr. World Environ.12(2), 317-325.

Turaga, J. (2015): Birds and trees in an urban context: An ecosystem paradigm for Vasant Vihar, New Delhi, India. Indian Birds,10: $3 \& 4,85-93$. 